\title{
Particular Reasons
}

\section{Citation}

Berker, Selim. 2007. Particular Reasons. Ethics 118(1): 109-139.

\section{Published Version}

http://dx.doi.org/10.1086/521586

\section{Permanent link}

http://nrs.harvard.edu/urn-3:HUL.InstRepos:2664288

\section{Terms of Use}

This article was downloaded from Harvard University's DASH repository, and is made available under the terms and conditions applicable to Other Posted Material, as set forth at http:// nrs.harvard.edu/urn-3:HUL.InstRepos:dash.current.terms-of-use\#LAA

\section{Share Your Story}

The Harvard community has made this article openly available.

Please share how this access benefits you. Submit a story.

\section{Accessibility}




\section{Particular Reasons*}

\section{Selim Berker}

\section{INTRODUCTION: FROM MONISM TO PLURALISM TO PARTICULARISM}

According to contemporary physics, there are four fundamental forces: the strong nuclear, weak nuclear, electromagnetic, and gravitational. One of the greatest successes of twentieth-century physics was the realization that the electromagnetic and weak nuclear forces could be unified into one-that they could be understood as two aspects of a single electroweak force. This discovery led to attempts at formulating a 'grand unified theory', as it came to be called, that would unify the three forces other than gravity. And now the search is on for an even more ambitious theory, a so-called theory of everything uniting all four fundamental forces. Perhaps some version of string theory will produce such a theory; perhaps some other, as yet unthought of theory will do the trick. But although progress has been hampered by our current lack of experimental evidence for the hypotheses being proposed, most practicing physicists are confident that a unified theory of the four fundamental forces is out there to be found.

There is a long-standing tradition in ethics with similar aspirations. On this approach, ethics is seen as involving a search for a grand unified theory of the moral realm, a quest for a "supreme principle of morality" (as Kant called it) that would constitute a theory of everything with respect to right and wrong. This single, universal principle could then be used to discover which of the actions available to us in a given circumstance are right and which are wrong and also to justify (both to ourselves and to others) why, exactly, the right actions are right and the wrong ones are wrong. The two best-known attempts at such a

* For helpful discussions of or comments on earlier versions of this article, many thanks to Jake Beck, Alex Byrne, Tyler Doggett, Andy Egan, Ned Hall, Caspar Hare, Richard Holton, Christine Korsgaard, Bernhard Nickel, Nic Southwood, Robert Stalnaker, Eric Swanson, Judith Jarvis Thomson, Steve Yablo, Seth Yalcin, and an audience at the Australian National University. Many thanks also to two anonymous referees (one of whom identified himself as Michael Ridge) and to the associate editors of Ethics.

Ethics 118 (October 2007): 109-139

(C) 2007 by The University of Chicago. All rights reserved. 0014-1704/2007/11801$0002 \$ 10.00$ 
principle are Kant's Categorical Imperative and Bentham's principle of utility, but this tradition lives on to this day, with many contemporary Kantians and consequentialists, among others, actively searching for what they take to be the most plausible version of a grand unified theory of morality.

In the past century a growing number of moral philosophers have expressed dissatisfaction with this monist tradition according to which there must be a single fundamental principle of morality. Often influenced by Aristotle, these critics find the monist principles thus far proposed unbearably crude and contend that any attempt to reduce morality to a single principle will inevitably leave something out. Monism seems to assume that there exists a moral algorithm, and if only we knew it, we could turn the crank and deduce for any given situation what we should and should not do. ${ }^{1}$ But, these critics insist, morality isn't the sort of thing that can be reduced to an algorithm; it isn't the sort of thing that could in principle be programmed into a computer. Rather, what is supposedly needed to arrive at the correct moral verdict in a given situation is "moral wisdom"- a kind of sensitivity to the morally relevant considerations present in the case at hand and an ability to properly judge the right thing to do in light of those considerations.

Among the philosophers sympathetic to this sort of criticism of the monist tradition, some have chosen to embrace a pluralist approach to ethics such as that found in W. D. Ross's theory of prima facie duties or in some (but not all) forms of virtue ethics, where instead of one solitary moral principle there is posited to be a plurality of basic principlesan "unconnected heap of duties," to use David McNaughton's apt expression, ${ }^{2}$ that are all equally fundamental. These differing duties can in principle conflict, but in such cases there are claimed to be no finitely codifiable rules dictating which duty trumps or outweighs the others, for otherwise the basic principles together with the weighing rules could be conjoined into a single master principle. Instead, what is allegedly needed in cases of conflict is the ability to accurately judge whether, say, one's duty of beneficence to perform some action outweighs one's duty of justice to avoid it or whether it would be better in this situation to be honest than to be loyal. The hope is that by allowing for a plurality of equally fundamental moral principles we can better cover the entire moral landscape, while at the same time providing an ineliminable role for moral judgment in deciding what one ought to do in a given circumstance.

1. Note my use of the word 'seems' in this sentence: I take no stand in this article on whether monist theories really are committed to a judgment-free moral algorithm.

2. David McNaughton, “An Unconnected Heap of Duties?” Philosophical Quarterly 46 (1996): 433-47. 
In recent years, though, an even more radical break with the monist tradition has begun to develop. ${ }^{3}$ According to what has come to be known as "moral particularism," even the pluralist's search for a multitude of basic moral principles is in vain. It's not that we need seven or twenty-seven or even 207 fundamental moral principles to fully capture the moral realm; rather, the particularist insists that no finite number of finite, exceptionless principles could account for all the truths there are about right and wrong, good and bad, virtue and vice. In the particularist's eyes, it's judgment all the way down: judgment as to which features of a given situation are morally relevant and judgment as to how the features that are morally relevant play off each other to determine what one should and should not do in that situation. If the particularist is right, any attempt to reduce morality to principles, even the sort of pro tanto principles appealed to by Rossian pluralists, will inevitably lead to error: the features that make something good are just so complicated, the conditions under which an action is right just so variegated, and the properties that make a person virtuous just so nuanced that the moral realm resists capture by any finite number of finite principles. Therefore, the pluralist's quest for a disconnected heap of duties is just as misguided as the monist's dream of a grand unified moral theory.

Such is the particularist's challenge to both monist and pluralist approaches to ethics. But it's one thing to have a sneaking suspicion that there are no substantive moral principles-one thing to place one's bets, as it were, on none ever being found-and quite another thing to adequately establish that this must be so. The main particularist strategy is to argue for their claims about principles by first attempting to secure

3. See Jonathan Dancy, "On Moral Properties," Mind 90 (1981): 367-85, "Ethical Particularism and Morally Relevant Properties," Mind 92 (1983): 530-47, Moral Reasons (Oxford: Blackwell, 1993), "The Particularist's Progress," in Moral Particularism, ed. Brad Hooker and Margaret Little (Oxford: Clarendon, 2000), 130-56, and Ethics without Principles (Oxford: Clarendon, 2004); Ulrik Kihlbom, Ethical Particularism: An Essay on Moral Reasons (Stockholm: Almqvist \& Wiksell, 2002); Mark Lance and Margaret Olivia Little, "Defeasibility and the Normative Grasp of Context," Erkenntnis 61 (2004): 435-55, "Defending Moral Particularism," in Contemporary Debates in Moral Theory, ed. James Dreier (Oxford: Blackwell, 2006), 305-21, and "Particularism and Antitheory," in The Oxford Handbook of Ethical Theory, ed. David Copp (Oxford: Oxford University Press, 2006), 567-94; Margaret Olivia Little, "Moral Generalities Revisited," in Hooker and Little, Moral Particularism, 276-304, "On Knowing the "Why': Particularism and Moral Theory," Hastings Center Report 31 (2001): 32-40, and "Wittgensteinian Lessons on Moral Particularism," in Slow Cures and Bad Philosophers: Essays on Wittgenstein, Medicine, and Bioethics, ed. Carl Elliott (Durham, NC: Duke University Press, 2001), 161-80; David McNaughton, Moral Vision (Oxford: Blackwell, 1988); and David McNaughton and Piers Rawling, "Unprincipled Ethics," in Hooker and Little, Moral Particularism, 256-75. The possibility of such a position was first pointed out and given the name 'particularism' in R. M. Hare, Freedom and Reason (Oxford: Clarendon, 1963), 18. 
certain claims about reasons. ${ }^{4}$ Particularists begin by taking for granted a widely held framework according to which reasons for action are the fundamental normative units whose interactions determine, through a metaphorical balancing of the weight of reason, all other normative properties of actions. They then argue that there is irremediable context dependence, both in how reasons for action arise out of the nonnormative features of a given situation and in how the reasons that are present combine to determine one's overall duties. From this they conclude that any proffered principle stating what in general grounds reasons for action, or how in general reasons for action play off each other to determine other normative notions, must either admit of exceptions or be infinite in length. Given their general framework, it follows that there do not exist - or, at least, that we should not expect there to existsubstantive finite and exceptionless moral principles of any variety.

In this article I raise a worry for the first stage of this strategy. Particularists assume a three-level framework according to which nonnormative facts at the first level determine the facts about reasons at the second level, which in turn determine other normative facts such as the overall rightness and wrongness of actions at the third level, and they want to claim that there is variability of an inscrutably complex sort both in how the second level depends on the first and in how the third level depends on the second. However, I will argue that once one builds this much variability into the framework, it begins to fall apart. The very notion of a reason for action depends on there being a certain level of constancy either in the connection between reasons and what grounds them or in the connection between reasons and one's overall duties, and when particularists posit as much variability as they do, we lose our grip on what they could mean when they call something a 'reason for action'. In short: the conjunction of the particularists' radical claims about the behavior of reasons leaves them without a coherent notion of a reason for action.

By considering this problem for particularism, we learn three valuable lessons. First, we learn that the particularists' challenge to monist and pluralist approaches to ethics has not, at least so far, been successfully made out. As there is significant reason to doubt the plausibility and even coherence of the particularists' views about reasons, their bold pronouncements should not give pause to those searching for the proper grand unified theory of morality or the most appropriate disconnected heap of duties. Second, we learn something about the reasons-based framework that is assumed not just by particularists but by many other contemporary writers as well. In particular, we learn that

4. For example, this is how the various portions of the particularist program are argued for by Dancy, Kihlbom, Lance, and Little in the works cited in n. 3 . 
this framework is not the presuppositionless starting point for ethical theorizing that it is sometimes taken to be but rather-since particularists cannot accept the framework while continuing to endorse every claim they make-has certain substantive assumptions about the structure of morality and the nature of reasons built into it. And third, we learn that particularism is perhaps best formulated without assuming that framework. As there is a tension between the particularists' claims about the ultimate uncodifiability of the moral realm and the reasonsbased framework's imposition of a general structure on that realm, it is more in the spirit of particularism for its adherents to renounce that framework altogether and attempt (if possible) to formulate particularism without it. ${ }^{5}$

\section{THE GENERALIZED WEIGHING FRAMEWORK}

Our main task will be to investigate the particularists' views about reasons for action. However, as particularists formulate those views within the confines of a certain normative framework, it will help to outline that framework first before laying out the particularists' own position on the nature of reasons. ${ }^{6}$

Suppose Andy is trying to decide which of two apartments to rent. How might he go about making that decision? One natural suggestion is that Andy should do something like the following. On a piece of

5. In this section I have characterized particularists as endorsing the view that there does not exist—or, at least, that we do not have good reason to believe that there existsa finite set of true, finite, and exceptionless principles that can fully cover the moral terrain. More recently, at least one particularist—namely, Jonathan Dancy—has backed off from this claim and instead formulated his position on principles as follows: "The possibility of moral thought and judgment does not depend on the provision of a suitable supply of moral principles" (Ethics without Principles, 7). However, this formulation is multiply ambiguous, and it is difficult to interpret Dancy's new position in such a way that it is not $(a)$ obviously false, $(b)$ equivalent to the formulation denying the existence of a sufficient number of true, finite, exceptionless principles, or $(c)$ so weak a claim that it can be accepted by nearly every monist and pluralist. For discussion, see Joseph Raz, "The Trouble with Particularism (Dancy's Version)," Mind 115 (2006): 99-120, 113-16; Sean McKeever and Michael Ridge, Principled Ethics: Generalism as a Regulative Ideal (Oxford: Clarendon, 2006), 19-20; and Michael Ridge and Sean McKeever, review of Ethics without Principles, by Jonathan Dancy, Philosophical Review 116 (2007): 124-28. Moreover, as my chief focus in this article will be on the issue of whether particularists can establish their claims about reasons, issues about how best to formulate their claims about principles will not be of direct concern to us.

6. See John Broome, "Reasons," in Reason and Value: Themes from the Moral Philosophy of Joseph Raz, ed. R. Jay Wallace, Philip Pettit, Samuel Scheffler, and Michael Smith (Oxford: Clarendon, 2004), 28-55, sec. 3, and John Horty, "Reasons as Defaults," Philosophers'Imprint 7 (2007), http://www.philosophersimprint.org/007003, sec. 1, for similar accounts of the general framework assumed by particularists (and others) in their discussions of reasons for action. 
paper he should make four columns and, in the first column, write down the positive elements, or 'pros', associated with taking the first apartment; in the second column, write down the negative elements, or 'cons', associated with taking the first apartment; in the third column, write down the pros of taking the second apartment; and, in the fourth column, write down the cons of taking the second apartment. Next, he should decide the weight of each item in the four columns-that is, decide how heavily each pro or con will affect his ultimate decision. Finally, he should survey the relative weights of the various pros and cons and come to a final decision about which option has the most favorable balance of considerations in its favor. Note that in this process Andy need not be able to represent the weight of each pro or con with anything as precise as a numerical value. Note, also, that the final determination of which option is the weightiest need not involve anything as mechanical as adding up the weights of a given option's pros and subtracting the weights of its cons in order to determine a total weight that can be compared with the total weight of the other option. But despite these deviations from a strict analogy with a weighing of masses on a scale, there still seems to be a useful sense in which we can say, metaphorically at least, that Andy is weighing his options-or, as it is commonly put, that he is weighing the reasons for and against each alternative to see where the balance lies.

According to what I will call the "generalized weighing model of practical deliberation," all practical deliberation does—or at least should-take the above form. Whenever an agent is in a given situation, there are a variety of actions that the agent might choose to perform in that situation. ${ }^{7}$ Each of these actions in turn possesses a variety of nonnormative properties, such as the property of causing pleasure in someone or the property of being a telling of a lie. According to the generalized weighing model, some of these nonnormative features give rise to a reason in favor of performing the action possessing them, and some of the features give rise to a reason against performing the action possessing them. ${ }^{8}$ Moreover, each of these reasons has a metaphorical

7. Following the particularists, I will be using the terms 'situation', 'circumstance', and 'context' interchangeably. The notion they are after is just the commonsense notion of a situation: one situation is the one I faced when I woke up this morning, another situation is the one you face right now as you read this sentence, and so on.

8. The type of reasons under consideration are sometimes called 'contributory reasons' or 'pro tanto reasons' to represent the fact that they need not be decisive reasons for a given course of action. (A slightly older term for the same notion is 'prima facie reason'- $\mathrm{a}$ term that was misleading since the entities in question are not merely "at first glance" reasons but retain their normative force even if outweighed.) For brevity I will usually omit the 'contributory' or 'pro tanto' qualifier.

Some authors make a distinction between peremptory (or requiring) reasons, which count 
weight or strength corresponding to how heavily it counts in favor of or tells against the action it counts in favor of or tells against. Finally, the generalized weighing model holds that each available action's overall moral status (such as its being right or wrong, obligatory or forbidden, permissible or supererogatory) can be determined by balancing the weights of the relevant reasons against each other in order to see where the overall weight of reason lies. ${ }^{9}$ When so construed, the generalized weighing model is a widely held conception of practical deliberation with an undeniable attraction to it; indeed, talk of reasons and their weights almost makes this model seem inevitable. ${ }^{10}$

As presented thus far, the generalized weighing model is an epistemological position concerning how one does (or should) determine the overall moral status of the actions available to an agent. However, it is also tempting to assume that the standard order of discovery during deliberation mirrors the metaphysical order of explanation-or in other words, it is tempting to make a slide from the epistemological claim that the overall balance of reason reveals which actions are right and which actions are wrong to the metaphysical claim that the overall balance of reason is what makes the right actions right and the wrong actions wrong (and similarly for other overall moral verdicts). According to what I will

toward the rightness of an action, and enticing reasons, which make an option attractive without having a bearing on its rightness; see Joseph Raz, "Explaining Normativity: Reason and the Will," in his Engaging Reason (Oxford: Oxford University Press, 1999), 90-117, and Jonathan Dancy, "Enticing Reasons," in Wallace et al., Reason and Value, 91-118. If this distinction is tenable (I have my doubts), then every occurrence of 'reason' in the body of this article should be replaced with 'peremptory reason'.

Finally, a note about the ontology of reasons: throughout I talk about the 'features' of an action as 'providing' (or 'giving rise to') reasons for or against performing that action and about the 'fact' that an action would have a given feature as 'being' a reason for or against performing that action. By taking reasons to be facts, I am regimenting our moral terminology in a way that not all theorists might endorse. However, nothing of consequence hangs on the particular regimentation I have settled on, and one can easily translate my talk of reasons as facts into a terminology adverting to one's ontological category of choice.

9. My discussion here concentrates on the overall moral status of actions, but the generalized weighing model is often applied more generally to the overall normative status of an action, such as its being what one ought (all things considered) to do or its being what it is most in one's interests to do. Particularists usually intend their claims to extend to these normative categories as well.

10. The two contemporary works most responsible, I believe, for making the generalized weighing model of deliberation as widely accepted as it currently is are Kurt Baier, The Moral Point of View: A Rational Basis of Ethics (Ithaca, NY: Cornell University Press, 1958), and Thomas Nagel, The Possibility of Altruism (Princeton, NJ: Princeton University Press, 1970), both of which quite explicitly endorse the model: see chap. 3 of the former and chap. 7 of the latter. A more recent endorsement of essentially the same model can be found in T. M. Scanlon, What We Owe to Each Other (Cambridge, MA: Harvard University Press, 1998), 65-66; and Derek Parfit, Climbing the Mountain (forthcoming). 
call the "generalized weighing model of morality," this latter metaphysical claim is indeed the case: the nonnormative features of the actions available to an agent in a given circumstance give rise to genuine metaphysical normative entities, called 'reasons for action', and the interplay of these reasons is what makes it such that the available actions have the overall moral status that they do.

To simplify our discussion, let us focus in this article on two overall moral statuses that an action might have, namely, that of being right and that of being wrong. Also, drawing on a partial analogy with chemistry that has become standard in the particularist literature, let us say that a reason for action has a positive or negative valence depending on whether it is a reason for or against action, respectively. Then on the generalized weighing model of morality, we can think of the metaphysical moral picture as having three layers to it:

1. The underlying level: the facts about the nonnormative properties of the actions available to a given agent in a given circumstance. ${ }^{11}$

2. The contributory level: the facts about the valences and weights of the reasons for and against performing each available action, which obtain in virtue of the facts at the underlying level.

3. The overall level: the facts about the rightness and wrongness of the available actions, which obtain in virtue of the facts at the contributory level. ${ }^{12}$

So once this model is in place, we can say that a nonnormative feature of an action that provides a reason for acting in that way is a "rightmaking feature" since it contributes toward the overall balance of reason in favor of that action being such as to make the action right. Similarly, a feature that provides a reason against an action can be said to be a "wrong-making feature." What determines the rightness and wrongness of actions on this conception is the overall balance of reason in favor of each, and what determines the reasons for and against each action are its nonnormative properties. To have a name for it, let us call the

11. In this article I assume that the underlying level consists of facts about the nonnormative properties of the actions available to an agent. However, McNaughton and Rawling (in their "Unprincipled Ethics") defend a theory according to which the facts at the underlying level that give rise to reasons for and against action at the contributory level are facts about the thick moral properties of actions. This complicates the picture but does not change anything important in the article's dialectic since presumably the thick moral properties themselves obtain in virtue of the nonnormative properties of the available actions.

12. Note that this talk of normative facts obtaining is all unabashedly realist sounding; indeed, I take it to be a basic assumption of the debate about particularism that moral realism holds. (Sometimes particularists insist that their talk of normative facts and properties can be construed minimalistically if one has antirealist persuasions, but whether this is really so is open to debate.) 
conjunction of the deliberative and metaphysical weighing models the "generalized weighing framework."

Two slightly more concrete examples will help illustrate how the generalized weighing framework works. Although classical utilitarians rarely talk of reasons for or against action, we can easily imagine one way of fitting hedonistic act utilitarianism (henceforth: utilitarianism) into the confines of the generalized weighing framework. According to such a version of utilitarianism, there are two nonnormative properties at the underlying level that give rise to reasons for and against action at the contributory level: the property of bringing about pleasure in someone, which always gives rise to a reason for action, and the property of bringing about pain in someone, which always gives rise to a reason against action. The 'always' here is important: on the utilitarian story, not only is the property of bringing about pleasure in someone right making, but it is necessarily right making (in every possible situation it provides a reason for action), and not only is the property of bringing about pain in someone wrong making, but it is necessarily wrong making (in every possible situation it provides a reason against action). Moreover, the utilitarian has a correspondingly simple story about what fixes the weight of a given reason: the weight of every reason for action is directly proportional to how much pleasure the action would bring about in the relevant person, and the weight of every reason against action is directly proportional to how much pain the action would bring about in the relevant person; indeed, we can even represent these weights with numbers if we wish. Finally, our utilitarian holds that the overall level is determined by the contributory level in the following manner: for each action, add up the numbers representing the weights of the reasons in favor of acting in that way and subtract the numbers representing the weights of the reasons against; the actions with the highest such total are right, and all other available actions are wrong.

A second ethical theory easily shoehorned into the generalized weighing framework is W. D. Ross's theory of prima facie duties. ${ }^{13}$ Adapted so as to involve explicit talk of reasons for action, Rossianism maintains that there are seven sets of nonnormative features that in every possible circumstance give rise to reasons for or against the actions possessing them. For instance, on this account it follows from Ross's prima facie duty of fidelity that the property of being a breaking of a promise always provides a reason against action, from his prima facie duty of self-improvement that the property of contributing to the improvement of

13. At least since the publication of J. O. Urmson, "A Defense of Intuitionism," Proceedings of the Aristotelian Society 75 (1975): 111-19, if not earlier, it has been common to reinterpret Ross's theory of prima facie duties as a theory of (contributory or pro tanto) reasons for action. 
one's intelligence always provides a reason for action, and so on, for all seven of Ross's prima facie duties. ${ }^{14}$ Thus, in regard to what determines the valence of a given reason, the Rossian story is similar to the utilitarian story, in that each posits a certain range of nonnormative features that are necessarily right or wrong making, although the Rossian list of such features is lengthier and of a more varied nature. Moreover, Ross insists that "the ground of the actual rightness of [an] act is that, of all acts possible for the agent in the circumstances, it is that whose prima facie rightness in the respects in which it is prima facie right most outweighs its prima facie wrongness in any respects in which it is prima facie wrong," which strongly suggests that he too would determine how the facts at the overall level depend on the facts at the contributory level through the simple additive procedure endorsed by the utilitarian. ${ }^{15}$

Where the Rossian account diverges in spirit from the utilitarian one is in how the weight of a given reason is determined. According to Ross, which of the various, possibly competing prima facie duties is most binding in a particular situation depends upon "the circumstances of the case" since "for the estimation of the comparative stringency of these prima facie obligations no general rules can . . . be laid down." ${ }^{16}$ Thus, on one plausible interpretation of Ross, he would hold that the relative weights of the reasons stemming from his prima facie duties vary from context to context: a nonnormative feature of an action that gives rise to a reason of one weight in one situation might give rise to a reason of a different weight in a different situation, depending on the details of the two cases. This is the sense in which Ross's theory provides an ineliminable role for judgment-as there are no general, context-independent rules for how the nonnormative features of an action determine the weights of the reasons for and against it, discerning the weight of an individual reason in a given situation requires judging how demanding that reason is in the current circumstance. ${ }^{17}$

\section{PARTICULARISM ABOUT REASONS FOR ACTION}

Particularists applaud Ross's inclusion of an ineliminable role for judgment in his theory but feel he did not go far enough. As mentioned before, for particularists it's judgment all the way down: not only judg-

14. See W. D. Ross, The Right and the Good (Oxford: Clarendon, 1930), 21, for the original list of Ross's seven prima facie duties.

15. Ibid., 46.

16. Ibid., 19, 41 .

17. I have mentioned two theories that can be easily fit into the generalized weighing framework, but it is worth noting that not all moral theories can be so easily fit into the framework. In particular, it is far from clear how to formulate Kantian ethical theories within the generalized weighing framework without doing major damage to both the content and intent of those theories. 
ment as to the weight of a given reason but also judgment as to the valence of a reason and judgment as to how the valences and weights of the relevant reasons play off each other to determine the overall moral status of the available actions. Jonathan Dancy, perhaps the most prominent particularist, summarizes the particularists' views about reasons as follows:

I see ethical particularism as merely one expression of an overall holism in the theory of normative reason. . . . Such an overall holism can be expressed as follows:

1. What is a reason in one situation may alter or lose its polarity [i.e., valence] in another.

2. The way in which the reasons here present combine with each other is not necessarily determinable in any simply additive way. ${ }^{18}$

Thus, particularism about reasons for action is a two-fold thesis: it concerns both the way in which reasons for action arise out of a situation's nonnormative features and the way in which the reasons for action that are present in a given situation combine to yield the overall moral status of the available actions. Let us consider each of these claims in turn.

According to what has come to be known as "holism about reasons for action," 19 the very valence of the reason (if any) provided by a given nonnormative feature of an action can alter as we change contexts. Here is one sort of example offered by particularists in support of this thesis: in most situations the fact that an action would bring the agent pleasure is a reason in favor of performing that action, but when Tyler tortures a cat for fun, the fact that doing so brings him pleasure is (allegedly) a reason against his acting in that way. Another example: in most situations the fact that I borrowed a book from you is a reason in favor of my returning it to you, but if you stole the book, then the fact that I borrowed the book from you is (allegedly) no reason at all for me to return it. The particularists' bold claim is that all reasons function in this way: for every fact that is a reason for action in one possible context, there is another possible context in which that same fact is either a reason against action or no reason at all, and an analogous claim is taken to hold for reasons against action. So whereas our utilitarian and Rossian theories identify certain necessarily right- and wrongmaking features, particularists insist that all right-making features are

18. Dancy, "Particularist's Progress," 132.

19. Some might find the use of the label 'holism' here a bit odd since the position in question is quite different from the other sorts of holisms that one finds in philosophy. However, by now the name "holism about reasons for action" (originally coined by Dancy) is too firmly entrenched in the philosophical lexicon to resist. 
only contingently right making, and all wrong-making features only contingently wrong making. In sum, particularists hold

holism about reasons for action: for every nonnormative feature of an action that gives rise to a reason for/against action in one possible context, there is another possible context in which that same feature either gives rise to a reason of opposite valence or else provides no reason one way or the other. ${ }^{20}$

Or as Margaret Little, another prominent particularist, puts it: "A consideration that in one context counts for an action, can in another count against it or be irrelevant."21

Holism about reasons for action concerns how the facts at the contributory level depend on the facts at the underlying level. The second half of particularism about reasons for action concerns how the facts at the overall level depend on the facts at the contributory level. Let us call the function that takes as input the valence and weight of all the reasons present in a given possible situation and gives as output the rightness or wrongness of each action available in that situation the "combinatorial function"; given the generalized weighing model's as-

20. This formulation of holism about reasons for action may need to be qualified in two ways. First, in order to avoid certain cheap counterexamples in which one builds a complete description of a given context into the property being considered (e.g., the property of being a telling of a lie in such and such a situation, where the "such and such" provides an exhaustive description of some particular situation), particularists may need to restrict the holist thesis so that it pertains only to nonnormative features that can be specified "in finite or helpful propositional form." (The latter phrase is Little's; see "Moral Generalities Revisited," 280.) Second, even when the formulation has been qualified in this way, the word 'every' may need to be replaced with 'nearly every': recently Dancy has conceded that he might be forced to admit the existence of a "privileged few" reasons whose valence is not sensitive to context, "including probably the intentional inflicting of undeserved pain" (Dancy, "Particularist's Progress," 131; see also his Ethics without Principles, 77-78). As nothing I say about holism turns on whether it is qualified in these two ways, I ignore these complications in what follows. (An anonymous referee suggested to me a third possible qualification that might be needed to properly formulate holism: perhaps, following Dancy, Ethics without Principles, 77, and Pekka Väyrynen, "Moral Generalism: Enjoy in Moderation," Ethics 116 [2006]: 707-41, 712, holism about reasons for action is best formulated not as the thesis that all reasons for action can vary in valence but rather as the thesis that all reasons for action are variable qua reasons, even if some reasons for action happen to be invariant due to their particular content. However, even if we ignore the obscurities involved in this distinction between a reason's varying in valence due to its particular content and its varying in valence due to its nature as a reason, I find this formulation of holism to be unsatisfactory. In particular, it would allow that someone who endorses the utilitarian theory of reasons for action glossed in Sec. II could count as a holist about reasons for action, as long as that person thinks that, qua reasons, reasons for action are variable, though it just happens to turn out that, due to their content, all reasons for action are invariant.)

21. Little, "On Knowing the 'Why," 34. 
sumption that the facts at the contributory level determine the facts at the overall level, such a function must exist. ${ }^{22}$ Let us say that the ${ }^{23}$ combinatorial function is additive if it can be calculated by adding up the weights of the reasons in favor of each action and subtracting the weights of the reasons against and then assigning an overall moral status (right or wrong or neither) to a given action on the basis of comparing the total weight of reason in favor of that action to the total weight in favor of the other available actions. Now particularists are quite explicit in denying that the combinatorial function is additive. ${ }^{24}$ Moreover, the particularists' general rhetoric makes it clear that they intend to deny that the combinatorial function can be written down in any finite formula, additive or otherwise. ${ }^{25}$ In other words, particularists hold

22. Shelly Kagan uses the expression "governing function" for much the same notion in "The Additive Fallacy," Ethics 99 (1988): 5-31, 14, and then goes on to argue that this function is not additive. Nagel (in Possibility of Altruism) prefers the term 'combinatorial principle', but there is a worry that this choice of terminology begs the question against the particularist by assuming that the combinatorial function can be represented as a finitely expressible principle.

23. Note my talk of 'the' combinatorial function, as opposed to 'a' combinatorial function: since I am using the term 'function' in the mathematical sense, there is only one combinatorial function, which holds for all contexts. Suppose I ask you to think of two natural numbers and either add the numbers together if they're both even or multiply them if at least one is odd. Have I just defined one function or two functions that change depending on which numbers you choose? In the mathematical sense, there is only one function here-only one mapping from the set of pairs of numbers you might choose to the set of numbers you might end up with after you have done what I tell you to do. One way of representing this function is as follows:

$$
f(x, y)= \begin{cases}x+y & \text { if } x \text { and } y \text { are even, } \\ x \times y & \text { otherwise. }\end{cases}
$$

Similarly, I intend there to be only one combinatorial function. Even if, intuitively, reasons combine one way in some contexts and combine a different way in other contexts, this can always be represented by a single function from the morally relevant factors in any given possible context to the rightness and wrongness of the actions available in that context.

24. In addition to the passage already quoted from Dancy ("The way in which the reasons here present combine with each other is not necessarily determinable in any simply additive way"; "Particularist's Progress," 132), Dancy denies that "once one has assessed the separate weight of each element, evaluative judgment consists of adding up the pros and cons to see which side is weightier" (Ethics without Principles, 190), and Little rejects a view according to which each moral reason "goes in the hopper to be weighed against whatever other independent factors happen to be present" ("Moral Generalities Revisited," 280). See also Dancy, Ethics without Principles, 15, 105-6, 127, 143.

25. Little, "Moral Generalities Revisited," 279 n. 3: "I'm reserving the 'particularist' label for those who deny codification at both levels [i.e., at both the contributory and the overall level]," and "Wittgensteinian Lessons on Moral Particularism," 166-67: "The particularist begins by rejecting attempts to codify relations between nonmoral and moral properties. The resultant picture also leads to a rejection of efforts to systematize relations 
noncombinatorialism about reasons for action: the combinatorial function for rightness and wrongness is not finitely expressible (and so, in particular, not additive).

Thus, for particularists, reasons for action are inextricably context dependent twice over: which nonnormative features give rise to reasons for or against action varies from context to context, and how the various reasons that are present combine to yield the overall rightness and wrongness of actions also varies from context to context. ${ }^{26}$ Together, the twin theses of holism and noncombinatorialism about reasons for action make up the view that I am calling "particularism about reasons for action."

\section{A NEWTONIAN ANALOGY}

Eventually I am going to argue that once they embrace both halves of particularism about reasons for action, particularists no longer have available to them a coherent notion of a reason for action. First, though, let us consider an analogy to help bring out the point.

We can think of the model of reasons that the particularists oppose as being akin to the following simplified version of Newtonian classical mechanics. Suppose we have a number of massive point particles in empty space that are interacting with each other purely through the classical law of gravitation. Then each particle exerts a force on every other particle that is determined solely by the masses of the two particles and their relative positions. ${ }^{27}$ So in any situation in which a particle of mass $m_{1}$ is at coordinates $\left(x_{1}, y_{1}, z_{1}\right)$ and a second particle of mass $m_{2}$ is at coordinates $\left(x_{2}, y_{2}, z_{2}\right)$, the individual force exerted on the first particle by the second is the same in both magnitude and direction, regardless of the mass and position of any other particles that may or may not be present in that situation. This is analogous to the claim, denied by holism

among moral properties." Dancy's discussion in Ethics without Principles of Kagan's "The Additive Fallacy" makes it clear that he too intends to deny that there is a finitely expressible combinatorial function: "For the particularist, it is going to be variability all the way down" (Ethics without Principles, 10). See also McNaughton and Rawling, "Unprincipled Ethics," 260 n. 12, where they claim that "the relation between an agent's reasons and her obligations is, we think, complex" and insist that there is "no weighing algorithm" for reasons.

26. It is important to notice that the type of context dependence at issue here is very different from the sort of context dependence at issue in debates about epistemic contextualism. Unlike contextualists in epistemology, particularists are not making a semantic claim about how a given word such as 'knowledge' or 'reason' picks out a different relation in different contexts; rather, the context in question is the context of the subject, not the context of utterance.

27. More precisely, the force acting on some particle 1 due to another particle 2 always points in the direction of particle 2 and always has a magnitude of $F=G m_{1} m_{2} / r^{2}$, where $m_{1}$ is the mass of particle $1, m_{2}$ is the mass of particle $2, r$ is the distance between the two particles, and $G$ is the universal gravitational constant. 
about reasons for action, that there are certain features of actions that always give rise to an individual reason for or against performing the action bearing that feature, regardless of what other features may or may not be present. Moreover, in our Newtonian model, the total force acting on a given particle is determined by a vector sum of the individual forces acting on that particle due to every other particle in the situation. This is analogous to the claim, denied by noncombinatorialism about reasons for action, that we can determine the total reason in favor of each action by adding up the weights of the individual reasons for and against performing that action.

We can easily imagine what a particularistic version of this Newtonian model would look like. As before, we have various massive point particles moving around in an empty three-dimensional space. However, for any given configuration of particles, the individual force acting on one particle due to another is not given by any general formula that holds regardless of the positions and masses of the other particles. Suppose that in one configuration there is a certain individual force acting on a particle of mass $m_{1}$ at coordinates $\left(x_{1}, y_{1}, z_{1}\right)$ due to a second particle of mass $m_{2}$ at coordinates $\left(x_{2}, y_{2}, z_{2}\right)$. Then there is no assurance that in any other configuration in which those two particles have the same mass and are at the same position, the individual force acting on the first particle due to the second is the same: depending on the positions and masses of the various other particles in the configuration, the first might have no force exerted on it by the second, or it might even have a force in the opposite direction exerted on it. This is the holist element in the model. But we can also build in a noncombinatorialist element, so that there is no finitely expressible formula, additive or otherwise, for determining how the individual forces being exerted on a given particle combine to yield the total force that the particle is subject to. In some configurations the total force acting on a particle might be a vector sum of the individual forces acting on it, but in other configurations the total force might be a cross product of the individual forces acting on the particle, or it might be a cross product added to another cross product, or it might be something even more complicated, depending on the intricacies of the case at hand.

However, it should be clear that, once we include both the holist and the noncombinatorialist ingredients in our Newtonian model, we begin to lose sight of what this notion of an individual force even amounts to. What does it mean to say that, in this model, one particle exerts an individual force in a given direction on a second particle? It doesn't mean that if no other forces were acting on the second particle, then it would accelerate in the direction of the individual force because (due to the holist element in the model) the nature of the individual force acting on the second particle is dependent upon the other forces 
acting on it as well. It doesn't mean that if the individual force were not present, then the second particle would tend to accelerate in the direction opposite to the individual force because (also due to the holist element in the model) the other individual forces acting on the second particle could potentially change if the individual force due to the first were removed. And it doesn't mean that there is a contribution in the individual force's direction to the total force acting on the second particle (a contribution that "counts in favor" of the total force being in that direction, as we might put it) because (due to the noncombinatorialist element in the model) the total force acting on a particle is not always a vector sum of the individual forces acting on it. So what, then, does this notion of an individual force being exerted on a particle amount to?

Thus, once we build the holist and noncombinatorialist elements into our Newtonian model, we lose our grip on what it means for one particle to exert an individual force on another. Similarly, I maintain, once particularists build both their holist and noncombinatorialist elements into the generalized weighing framework, we lose our grip on what they mean by a reason for or against action. ${ }^{28}$

\section{DO PARTICULARISTS HAVE A COHERENT NOTION OF A REASON FOR ACTION?}

Recall the three-level generalized weighing framework within which particularists formulate their claims about how reasons work: according to that framework, certain nonnormative features of the actions available to an agent provide reasons of various valences and weights for and against performing those actions (the dependence of the contributory level on the underlying level), and the overall moral status of the available actions is determined in virtue of the valences and weights of those reasons (the dependence of the overall level on the contributory level). Thus, within this framework, the contribution of an individual reason for action to the entire system is exhausted by two roles it plays: (i) some nonnormative feature of an action gives rise to that reason, and (ii) that reason counts one way or the other toward the rightness or wrongness (as well as other overall moral verdicts) of the action bearing that feature. However, particularists insist that each

28. Some particularists might try to deny that the particularistic Newtonian model just described is really analogous to a particularistic theory of reasons for action. However, all parties should agree that a nonparticularistic theory of reasons for action is analogous to the nonparticularistic Newtonian model. Moreover, I put forward that the ways in which a particularistic theory of reasons for action deviates from a nonparticularistic one are exactly analogous to the ways in which the particularistic Newtonian model deviates from a nonparticularistic one. It follows that particularists must concede that their theory of reasons is analogous to the particularistic Newtonian model. 
of these defining roles is inscrutably context dependent. As particularists see it, reasons for action are context dependent both "from below" and "from above": context dependent "from below" since whether a given nonnormative feature gives rise to a reason for or against action varies from context to context (holism about reasons for action), and context dependent "from above" since how the reasons present in a given circumstance combine to determine the overall moral status of the actions available in that circumstance varies from context to context (noncombinatorialism about reasons for action). But then particularistic reasons for action would appear to be free-floating $\operatorname{cog}$ s in the normative machinery, and it becomes difficult to understand what particularists even mean when they call something a 'reason for action' or a 'reason against action'.

According to one common conception, a reason for action is a consideration that would decisively count in favor of a given action were no other reasons present. So on this view, which we might call the "isolation conception of a reason for action," the fact that action X would have feature $\mathrm{F}$ in circumstance $\mathrm{C}$ qualifies as a reason for performing $\mathrm{X}$ in $\mathrm{C}$ if and only if, in any possible situation in which $\mathrm{F}$ is the only morally relevant feature of the actions available to the agent, the actions possessing $\mathrm{F}$ are the right thing to do: when no other moral considerations are present, a reason for action "carries the day." Similarly, on this conception, the fact that action $\mathrm{Y}$ would have feature $\mathrm{G}$ in circumstance $\mathrm{D}$ qualifies as a reason against performing $\mathrm{Y}$ in $\mathrm{D}$ if and only if, in any possible situation in which feature $G$ is the only morally relevant feature of the actions available to the agent, the actions possessing $\mathrm{G}$ are the wrong thing to do. However, it just falls out of this conception of what it is to be a reason for or against action that the holist half of particularism about reasons for action is false. Suppose the fact that a given action would be a telling of a lie is a reason against performing that action in some circumstance $\mathrm{C}$. Then given the isolation conception, it follows that in any situation in which the property of being a telling of a lie is the only morally relevant feature of the actions available in that situation, those actions that involve telling a lie are wrong. But this in turn implies that the fact that an action would be a telling of a lie is a reason against performing that action in every circumstance, not just $\mathrm{C}$, for in every circumstance it is now the case that, were the property of being a telling of a lie the only morally relevant feature of the actions available to the agent, the actions possessing that property would be wrong. Thus, the isolation conception entails, contra the claims of holism, that whenever some feature provides a reason against action in one possible context, that feature must provide a reason against action in every possible context. For this reason, particularists 
who endorse holism cannot accept the isolation conception of a reason for action.

According to a second possible conception, which we might call the "removal conception of a reason for action," a reason for action is a consideration whose removal would make the action in question less right, and a reason against action is a consideration whose removal would make the action less wrong. More precisely, on this conception the fact that action $\mathrm{X}$ would have feature $\mathrm{F}$ in circumstance $\mathrm{C}$ is a reason for (or against) action $\mathrm{X}$ if and only if, for any sufficiently similar circumstance $\mathrm{C}^{\prime}$ in which $\mathrm{X}$, if performed, would have all the same morally relevant features except $\mathrm{F}, \mathrm{X}$ is less right (or less wrong) in $\mathrm{C}^{\prime}$ than in C. In a sense, then, this proposal is the converse of the previous one: in order to determine whether a given feature of an action gives rise to a reason for or against performing that action, we remove only the feature in question and see how the rightness or wrongness of the action varies, rather than remove every other morally relevant feature. Now there are difficulties making precise how all of this should go. For example, the proposal implicitly assumes that rightness and wrongness come in degrees (which one might contest), and something needs to be said about how in general one is to strip away the feature being evaluated while holding all other morally relevant features constant. (It is clear enough what one is to do when determining whether the property of, say, producing pleasure gives rise to a reason in favor of actionsimply make the action less pleasurable and see whether the rightness of the action in turn diminishes-but in most other cases it is far less clear how to "cleanly excise" the property being assessed.) However, we can sidestep these issues, because regardless of how they are resolved, the particularists' holism prohibits them from being able to make use of the removal conception.

The whole point of holism about reasons for action is that the valence of the reason provided by a given feature of an action is determined by other features of the case at hand, not by features of the action (such as its comparative rightness or wrongness) in certain counterfactual situations. Holism holds that in a counterfactual situation in which we remove only the feature being scrutinized, this change might lead to any number of other changes in the valences and strengths of the reasons provided by other features of the available actions; thus, given holism, the method invoked by the removal conception will be unable to isolate the individual contribution made by the specific feature being considered. The following example is used by Dancy to illustrate this very point:

Consider a case in which I am thinking of doing something for a friend. My action, were I to do it, would be good, and partly good 
because it is an expression of our friendship. But now, if I were to be doing the action and not doing it for a friend, I would presumably be doing it for someone who is not a friend, and it might be that doing it for someone who is not a friend is even better than doing it for a friend. . . . Our friendship seems to be a reason to do the action even though if we were not friends I would have even more reason to do it. ${ }^{29}$

The example is intended to work as follows: in one situation the fact that an action would be one done for a friend might be a reason to perform that action, even though one has more overall reason to perform the action (and hence, the action is more right) in some sufficiently similar situation whose only relevant difference is that the person in question is not one's friend. Now Dancy's interpretation of this particular pair of cases is controversial, but even if one rejects that interpretation the main point remains: holists about reasons for action will want to allow for the possibility that pairs of cases might exist that have the general structure Dancy alleges these two cases to have, but the removal conception rules out the possibility of such cases from the outset, so holists about reasons for action cannot avail themselves of this conception of a reason for action. ${ }^{30}$

According to a third possible conception, a reason for action is a consideration that counts in favor of a certain course of action being the right thing to do, and a reason against action, a consideration that counts against. So on this story, which we might call the "right-making conception of a reason for action," a reason for performing action X contributes positively toward X being right in the given circumstance, and a reason against performing action $\mathrm{X}$ contributes negatively toward $\mathrm{X}$ being right in the given circumstance (i.e., contributes positively toward $\mathrm{X}$ being wrong in that circumstance). However, particularists cannot hold this conception of a reason for action, either. The problem is that talk of a reason being a consideration counting in favor of or against a certain action being the right thing to do makes the most sense when there is an additive combinatorial function; the more we deviate from an additive combinatorial function, the more obscure such talk becomes.

In order to show why this is so, it will help if we get a little more formal. Suppose there are only two nonnormative features of actions that give rise to reasons for or against action: $\mathrm{F}_{1}$ and $\mathrm{F}_{2}$. If $\mathrm{X}$ is an action

29. Dancy, Ethics without Principles, 20.

30. Little makes the same point: "If we accept the doctrine of holism, the implication of changing one variable is influenced, in ways that defy codification, by differences in the other variables' values. We cannot isolate the implication of switching from truthtelling to lying by holding other variables constant, for it matters what the substantive content of those variables was in the first place" ("Moral Generalities Revisited," 290). See also Jonathan Dancy, "Defending Particularism," Metaphilosophy 30 (1999): 25-31, 31. 
available to an agent in circumstance $\mathrm{C}$, let $r_{1}(\mathrm{X}, \mathrm{C})$ be a real number representing the valence and weight of the reason, if any, provided by $X$ 's possessing feature $F_{1}$ in the following manner:

If $\mathrm{X}$ would possess $\mathrm{F}_{1}$ if performed in $\mathrm{C}$, and that fact is a reason for performing $\mathrm{X}$ in that context, then $r_{1}(\mathrm{X}, \mathrm{C})>0$, and its absolute value represents the weight of the reason so provided.

If $\mathrm{X}$ would possess $\mathrm{F}_{1}$ if performed in $\mathrm{C}$, and that fact is a reason against performing $\mathrm{X}$ in that context, then $r_{1}(\mathrm{X}, \mathrm{C})<0$, and its absolute value represents the weight of the reason so provided.

Otherwise, $r_{1}(\mathrm{X}, \mathrm{C})=0$.

Moreover, let $r_{2}(\mathrm{X}, \mathrm{C})$ represent in a similar way the valence and weight of the reason, if any, provided by X's possessing feature $\mathrm{F}_{2}$ if performed in $\mathrm{C}$. Then if there is an additive combinatorial function, we can represent the total reason in favor of action $\mathrm{X}$ in circumstance $\mathrm{C}$ as follows:

$$
t(\mathrm{X}, \mathrm{C})=r_{1}(\mathrm{X}, \mathrm{C})+r_{2}(\mathrm{X}, \mathrm{C}) .
$$

Finally, let the actions available to the agent in circumstance $\mathrm{C}$ that maximize this function be the right ones to do in that circumstance, and let all other available actions be the wrong ones to do. ${ }^{31}$

When we determine the rightness or wrongness of actions from the valences and weights of the relevant reasons in this way, it is readily transparent why reasons for a given action are considerations that count in favor of that action being right and reasons against are considerations that count in favor of it being wrong. Since $r_{i}(\mathrm{X}, \mathrm{C})$ is always positive when a reason for action is provided by $\mathrm{X}$ 's possessing $\mathrm{F}_{i}$, reasons in favor of performing $\mathrm{X}$ always add to the total reason in favor of $\mathrm{X}$ in C. And since $r_{i}(\mathrm{X}, \mathrm{C})$ is always negative when a reason against action is provided by $\mathrm{X}$ 's possessing $\mathrm{F}_{i}$, reasons against performing $\mathrm{X}$ always subtract from the total reason in favor of $\mathrm{X}$ in $\mathrm{C}$. So when the combinatorial function is additive, it is perfectly natural to talk about a reason in favor of some action being an individual positive contribution toward its rightness and a reason against that action being an individual positive contribution toward its wrongness.

For some ways of deviating from a strictly additive combinatorial function, the naturalness of this way of talking is preserved. For example, suppose there are still only two nonnormative features, $F_{1}$ and $F_{2}$, that

31. Thus, if $\mathrm{I}$ is an index set that ranges over the indices for all the actions $\mathrm{X}_{i}$ available to the agent in circumstance $\mathrm{C}$, the combinatorial function can be represented in its full glory as follows:

$$
f\left(\mathrm{X}_{i}, \mathrm{C}\right)= \begin{cases}\text { right } & \text { if }(\forall j \in \mathrm{I})\left[t\left(\mathrm{X}_{i}, \mathrm{C}\right) \geq t\left(\mathrm{X}_{j}, \mathrm{C}\right)\right] \\ \text { wrong } & \text { otherwise }\end{cases}
$$


ever give rise to reasons for or against action, but the total reason in favor of action $\mathrm{X}$ in context $\mathrm{C}$ is instead determined as follows:

$$
t^{\prime}(\mathrm{X}, \mathrm{C})=\left[r_{1}(\mathrm{X}, \mathrm{C})\right]^{3}+r_{2}(\mathrm{X}, \mathrm{C}) .
$$

As before, the right actions are those that maximize the total reason function, and the wrong actions those that do not. And since $\left[r_{1}(\mathrm{X}, \mathrm{C})\right]^{3}$ is always positive when $r_{1}(\mathrm{X}, \mathrm{C})$ is positive and always negative when $r_{1}(\mathrm{X}, \mathrm{C})$ is negative, it still makes sense to talk about the reasons of positive valence provided by feature $F_{1}$ counting in favor of the rightness of the action possessing that feature and the reasons of negative valence provided by feature $\mathrm{F}_{1}$ counting against the action's rightness. However, suppose instead that the total reason function is determined like so:

$$
t^{\prime \prime}(\mathrm{X}, \mathrm{C})=\left[r_{1}(\mathrm{X}, \mathrm{C})\right]^{2}+r_{2}(\mathrm{X}, \mathrm{C}) .
$$

Now we have trouble. If the fact that $\mathrm{X}$ would have feature $\mathrm{F}_{1}$ is a reason against performing $\mathrm{X}$ in $\mathrm{C}$, then although $r_{1}(\mathrm{X}, \mathrm{C})$ is negative, $\left[r_{1}(\mathrm{X}, \mathrm{C})\right]^{2}$ is positive, so that fact adds to the total reason in favor of $\mathrm{X}$ and hence counts in favor of, not against, $\mathrm{X}$ being right in the given circumstance. In other words, given this way of combining reasons to determine overall rightness and wrongness, whenever feature $F_{1}$ provides a reason against action in a given context, that feature is actually right making in that context. For this reason we are no longer operating with the right-making conception of a reason for action. And a similar point applies if instead the total reason function is a multiplicative function like the following:

$$
t^{\prime \prime \prime}(\mathrm{X}, \mathrm{C})=r_{1}(\mathrm{X}, \mathrm{C}) r_{2}(\mathrm{X}, \mathrm{C}) .
$$

Suppose $\mathrm{X}$ would have feature $\mathrm{F}_{1}$ if performed in $\mathrm{C}$, and that fact is a reason for performing $\mathrm{X}$ in $\mathrm{C}$. Then $r_{1}(\mathrm{X}, \mathrm{C})$ is positive, but whether this positively or negatively affects the total reason in favor of $\mathrm{X}$ in $\mathrm{C}$ now depends on the sign of $r_{2}(\mathrm{X}, \mathrm{C})$ and hence depends on the valence of the reason (if any) provided by the other feature, $\mathrm{F}_{2}$. In this case, talk of a reason for action as being a consideration that always counts in favor of the rightness of that action has become strained at best. ${ }^{32}$

I take these examples to show that one cannot hold the right-making conception of a reason for action while allowing that the combinatorial function determining rightness and wrongness can have any old form whatsoever. In order to make sense of the idea that reasons for action always contribute toward an action's rightness and reasons against always

32. Kagan makes much the same point when he notes that without what he calls the "additive assumption" (in effect, the assumption that there is an additive combinatorial function), any talk of "contributions" made by individual morally relevant factors seems out of place ("Additive Fallacy," 17). 
contribute toward its wrongness, we need the combinatorial function to be such that (i) individual reasons always make discernible individual contributions to the overall rightness or wrongness of a given action and (ii) the individual contribution made by a reason of positive valence always positively affects the total reason in favor of the action in question, and the individual contribution made by a reason of negative valence always negatively affects the total reason in favor of the action. Let us call the combinatorial function "quasi-additive" if, like the combinatorial function constructed from the total reason function $t^{\prime}(\mathrm{X}, \mathrm{C})$ above, it satisfies these two criteria. ${ }^{33}$ It is important to notice that the vast majority of possible combinatorial functions are neither additive nor quasi-additive. ${ }^{34}$ However, those who endorse the right-making conception must hold, on pains of having an incoherent notion of a reason for action, that the combinatorial function is, if not additive, then at least quasi-additive. It follows from the particularists' noncombinatorialism that the combinatorial function is not additive. Moreover, it is not clear what grounds particularists have to insist that, although we don't know enough about the combinatorial function to be able to write it down in finite form, we do know enough about it to know that it is quasi-additive. This puts particularists who endorse both noncombinatorialism and the right-making conception in a precarious position: the coherence of their very notion of a reason for action depends on there being a quasi-additive combinatorial function, but it is difficult to see what means they have of establishing that there

33. Note that on this way of characterizing what makes a combinatorial function quasi-additive, all additive combinatorial functions also count as quasi-additive. The definition of quasi-additivity provided here is admittedly vague, but it will do for present purposes. Indeed, I suspect it is not possible to be any more precise in characterizing quasi-additivity without making various assumptions about the combinatorial function that would not be accepted by all moral theorists. For example, if we can represent the valence and weight of every distinct reason by a variable $r_{i}$ in the way described in the text and if the combinatorial function can be calculated in terms of a total reason function, $t\left(r_{1}, r_{2}, \ldots r_{n}\right)$, that is a function of the reason variables and if that total reason function is differentiable at every point with respect to each of those variables, then I put forward that the combinatorial function is quasi-additive if and only if the following obtains for each $i$ such that $1 \leq i \leq n$ :

$$
\frac{\partial t}{\partial r_{i}} \geq 0 \text { for all values of } r_{1}, r_{2}, \ldots r_{n} .
$$

However, this precise a formulation of quasi-additivity comes at the cost of some fairly substantial-and controversial-assumptions about the nature of the combinatorial function. (It is interesting to note that, given this formulation of what it takes for the combinatorial function to be quasi-additive, the requirement that the combinatorial function be quasi-additive is equivalent to the requirement that reasons for action satisfy the removal conception.)

34. This point is only bolstered if we do not assume, as I did in the examples of the past few paragraphs, that the weight of a given reason can be represented by a real number. 
is one without conceding that the combinatorial function might, after all, be finitely expressible. Conclusion: because of their commitment to noncombinatorialism, particularists are not entitled to hold the rightmaking conception of a reason of action..$^{35}$

Could particularists resist this line of argument by insisting that it is an analytic truth that the combinatorial function is quasi-additive? I doubt it. Even if we ignore Quinean concerns about analyticity, the purported analytic truth is far more recherche than the sorts of things that are usually held to be true merely in virtue of the meaning of the terms involved. ${ }^{36}$ Moreover, if we allow that we can know by studying

35. Objection: It is possible to construct a combinatorial function that is quasi-additive but not finitely expressible by splicing together several quasi-additive combinatorial functions in an uncodifiable manner. For example, particularists could insist that in some contexts the total reason function is given by $t(\mathrm{X}, \mathrm{C})$, that in other contexts the total reason function is given by $t^{\prime}(\mathrm{X}, \mathrm{C})$, and that there is no cashing out in finite terms when one of these two total reason functions applies. As each of these total reason functions satisfies the conditions for quasi-additivity, it follows that the resulting combinatorial function will be quasi-additive but not finitely expressible.

Reply: It is a mistake to assume that just because the combinatorial function constructed from total reason function $t_{1}(\mathrm{X}, \mathrm{C})$ is quasi-additive and the combinatorial function constructed from total reason function $t_{2}(\mathrm{X}, \mathrm{C})$ is quasi-additive, the combinatorial function constructed from the following total reason function must be quasi-additive:

$$
t_{3}(\mathrm{X}, \mathrm{C})= \begin{cases}t_{1}(\mathrm{X}, \mathrm{C}) & \text { if such and such conditions obtain, } \\ t_{2}(\mathrm{X}, \mathrm{C}) & \text { otherwise. }\end{cases}
$$

For example, as explained in the body of the article, we can construct an additive (and hence quasi-additive) combinatorial function from the following total reason function:

$$
t(\mathrm{X}, \mathrm{C})=r_{1}(\mathrm{X}, \mathrm{C})+r_{2}(\mathrm{X}, \mathrm{C}) .
$$

Moreover, in a similar way we can construct an additive (hence quasi-additive) combinatorial function from the following total reason function:

$$
t^{\prime \prime \prime}(\mathrm{X}, \mathrm{C})=r_{1}(\mathrm{X}, \mathrm{C})+r_{2}(\mathrm{X}, \mathrm{C})-500 .
$$

However, a combinatorial function constructed in the same way from the following total reason function is not quasi-additive:

$$
t^{*}(\mathrm{X}, \mathrm{C})= \begin{cases}r_{1}(\mathrm{X}, \mathrm{C})+r_{2}(\mathrm{X}, \mathrm{C})-500 & \text { if } r_{1}(\mathrm{X}, \mathrm{C})=10 \\ r_{1}(\mathrm{X}, \mathrm{C})+r_{2}(\mathrm{X}, \mathrm{C}) & \text { otherwise. }\end{cases}
$$

After all, $t^{*}(\mathrm{X}, \mathrm{C})$ is the same function, in the mathematical sense (see n. 23), as the following non-quasi-additive total reason function:

$$
t^{* *}(\mathrm{X}, \mathrm{C})= \begin{cases}-49 r_{1}(\mathrm{X}, \mathrm{C})+r_{2}(\mathrm{X}, \mathrm{C}) & \text { if } r_{1}(\mathrm{X}, \mathrm{C})=10 \\ r_{1}(\mathrm{X}, \mathrm{C})+r_{2}(\mathrm{X}, \mathrm{C}) & \text { otherwise }\end{cases}
$$

Therefore, patching together several quasi-additive combinatorial functions does not always yield a quasi-additive combinatorial function, and so the objection fails.

36. After all, recall (n. 33) how difficult it was to even characterize quasi-additivity. If it is not even clear how to precisely formulate quasi-additivity without making contentious assumptions about the nature of the combinatorial function, how could we possibly derive analytic platitudes merely from the meaning of the term 'quasi-additive'? 
the meaning of the relevant terms that the combinatorial function satisfies one constraint (that of being quasi-additive), this raises the question: why can't we also know by studying the meaning of the relevant terms that the combinatorial function satisfies various other constraints, enough of which might reduce it to finite form? Recall that the majority of possible combinatorial functions are not quasi-additive. So to require that the combinatorial function be quasi-additive is a fairly demanding restriction-a fairly sizable way of cutting down the space of possible combinatorial functions. Why, then, can't we appeal to more analytic truths to cut down the space of possible combinatorial functions even further? And why couldn't doing so eventually result in a finitely expressible combinatorial function? To insist that we can't reduce the combinatorial function to finite form but can know that it must be quasiadditive is like insisting, of some number with an infinite, nonrepeating decimal expansion, that we can't reduce that number to a finite formula, but we can know that a one never directly follows a zero in its infinitely long decimal expansion. ${ }^{37}$ Or closer to home, it is like insisting that, although we can know from the meaning of the terms involved that some principle of impartiality holds, that is the only nontrivial, exceptionless constraint we can know about rightness and wrongness. ${ }^{38}$ How we come to know that the combinatorial function must be quasi-additive is beside the point; what matters is that if we accept the right-making conception and its subsequent requirement that the combinatorial function be quasi-additive (whether through an appeal to analytic truths or on some other grounds), then this puts pressure on the particularists' adherence to noncombinatorialism.

According to a fourth and final conception of what it is to be a reason for action, which we might call the "favoring conception," a reason for action is a consideration that counts in favor of a given action, and a reason against action, one that counts against. ${ }^{39}$ The difference between this and the previous conception is that, whereas with the rightmaking conception we said that a reason for performing action $\mathrm{X}$ is a consideration that counts in favor of $X$ being the right thing to do, here we

37. Of course, we can prove similar things about some numbers (e.g., $\pi$ and $e$ ) that have infinite, nonrepeating decimal expansions, but in those cases there is always some way of expressing the number in question in a finite formula.

38. Note that I am not claiming that it is at all plausible that a principle of impartiality is an analytic truth; rather, what I am claiming is that if such a principle were an analytic truth, then it would be odd if there were no other analytic moral truths of that sort.

39. Joseph Raz, Practical Reason and Norms, 2nd ed. (Oxford: Oxford University Press, 1990), 186: "The reasons for an action are considerations which count in favor of that action"; Scanlon, What We Owe to Each Other, 17: "Any attempt to explain what it is to be a reason for something seems to me to lead back to the same idea: a consideration that counts in favor." 
are saying that a reason for performing $\mathrm{X}$ is a consideration that counts in favor of $X$ (full stop). It is tempting to think that at the end of the day there is little difference between these two conceptions of a reason for action. However, some philosophers-including many particularists-make a distinction between the "favoring relation" and the "rightmaking relation." Dancy makes the point as follows (although in this passage he focuses on the alleged difference between the favoring relation and the ought-making relation, the same reasoning, if it works, can establish a difference between the favoring relation and the rightmaking relation):

It seems to me that we are in fact dealing with two normative relations rather than one. The first is the relation between reasons and ought-judgments; we specify the reasons, and pass to the judgments that we ought to act. The second is a relation between reasons and action which is not necessarily mediated by any ought at all; it is the one that is in play when we engage in the sort of practical reasoning whose "conclusion" is an action. I don't always think, "There is this reason for jumping; so I ought to jump"; sometimes I just think, "There is this reason for jumping; so I'll jump." Crucially, the relation between reason and ought-judgment is different from the relation between reason and action. And it is really the latter that we are after when we try to understand the notion of a reason for action-a practical reason. ${ }^{40}$

Switching from talk of ought making to talk of right making, the idea here is that the favoring relation is a relation that holds between a reason and an action, whereas the right-making relation is a different normative relation that holds between a reason (or more accurately, a reason-giving feature) and an action's rightness or wrongness. However, note that once one endorses the generalized weighing model of morality (as particularists do), then feature $\mathrm{F}$ is a right-making feature of action $\mathrm{X}$ in circumstance $\mathrm{C}$ if and only if the fact that $\mathrm{X}$ would have $\mathrm{F}$ if performed in $\mathrm{C}$ is a reason for performing $\mathrm{X}$-and so, on the favoring conception, counts in favor of $\mathrm{X}$. Thus, even if technically the favoring and rightmaking relations are different relations, within the generalized weighing framework the favoring and right-making conceptions of a reason for action amount to much the same thing.

However, suppose I am wrong here, so that the favoring conception

40. Dancy, Ethics without Principles, 22-23. Dancy later makes it clear (78-79) that he intends there to be an analogous difference between the favoring relation and the rightmaking relation. This idea that there is a distinctive type of practical reasoning whose conclusion is an action, though Aristotelian in origin, has its modern roots in G. E. M. Anscombe, Intention (Oxford: Blackwell, 1957); for criticism of the idea, see Judith Jarvis (Thomson), "Practical Reasoning," Philosophical Quarterly 12 (1962): 316-28. 
is, in fact, a distinct conception of what it is to be a reason for action; even then the particularists' noncombinatorialism bars them from being able to hold the favoring conception. The idea behind this claim is as follows. Let us suppose there is a distinct type of practical reasoning that ends in an action, rather than a theoretical conclusion about what it would be right to do (or what one ought to do). Then, given the generalized weighing framework, which action is the correct conclusion of that piece of practical reasoning is determined by the weight and valence of the reasons that are (or should be) appealed to in that bit of reasoning. So, just as there is a combinatorial function that takes as input the valences and weights of the reasons present in a given situation and outputs the rightness and wrongness of the actions available in that situation, there is a combinatorial function that takes as input the valences and weights of the reasons that are (or should be) appealed to in a given piece of practical reasoning and outputs the action (or actions) that are the correct conclusions of that reasoning. And just as particularists hold that the first of these combinatorial functions is not finitely expressible, they no doubt would also hold that the second of these combinatorial functions is not finitely expressible-and in particular not additive in form. So we can run an argument exactly parallel to the one used to show that particularists cannot hold the right-making conception in order to establish that they cannot hold the favoring conception either.

All of which raises the question: what exactly do particularists think reasons for action are? Their holism about reasons for action blocks them from being able to hold the isolation and removal conceptions of a reason for action, and their noncombinatorialism blocks them from being able to hold the right-making and favoring conceptions. But then the particularists' notion of a reason for action is mysterious indeed. ${ }^{41}$

\section{GIVING UP NONCOMBINATORIALISM? OR MOVING BEYOND WEIGHING?}

I have just argued that if particularists accept both holism and noncombinatorialism, they are left with no coherent notion of a reason for

41. Does the argument just given assume that one must be able to give a reductive account of reasons for action? No, it does not. I was intentionally silent about whether the proposed conceptions involved reducing reasons to more fundamental notions or whether they allowed for the possibility that some of the terms in the account of a reason might not be definable except in terms of a reason. Thus, even if, following Scanlon, one endorses the favoring conception of a reason but insists that the favoring relation can be cashed out only in terms of the being-a-reason-for relation (so that one is a primitivist about both reasons and the favoring relation), it still follows that one is not entitled to adhere to the favoring conception unless the combinatorial function is quasi-additive, and that is all I needed in order to argue that particularists cannot hold the favoring conception. 
action. One natural line of response to this argument is as follows: "According to you, particularists can't endorse holism and noncombinatorialism at the same time. But who says they need to endorse both theses? Indeed, it seems that particularists can get most of what they want out of their position by accepting one of those two theses while denying the other. So in particular, since particularists spend a good deal more time discussing holism than they do discussing noncombinatorialism, why can't particularists maintain their allegiance to holism but give up any commitment to noncombinatorialism?" ${ }^{42}$

It is indeed open to particularists to adopt such a position, but I doubt that many true particularists would. One of the main forces driving some philosophers to become particularists is a general suspicion about the usefulness and value of the traditional quest for true and exceptionless moral principles, and if holism is true but noncombinatorialism is not, then there remains a significant place in ethics for at least one portion of that traditional quest. Given the three-level generalized weighing model of morality to which particularists are committed, there are three basic categories of moral principles explaining how the facts at one of the model's three levels are determined in general by the facts at one of the more basic levels:

underlying-to-contributory principles: principles specifying how in general the nonnormative facts at the underlying level determine the facts about the valences and weights of individual reasons at the contributory level,

contributory-to-overall principles: principles specifying how in general the facts about the valences and weights of individual reasons at the contributory level determine the facts about the rightness and wrongness of the available actions at the overall level, and

underlying-to-overall principles: principles specifying how in general the nonnormative facts at the underlying level determine the facts about the rightness and wrongness of the available actions at the overall level.

Thus, if particularists give up their noncombinatorialism, they must

42. One way of strengthening this objection would involve pointing out that we can distinguish between two forms of holism: valence holism, according to which the nonnormative features that give rise to reasons of one valence in one context also give rise to reasons of a different valence in other contexts, and weight holism, according to which the nonnormative features that give rise to reasons of one weight in one context also give rise to reasons of differing weights in other contexts. Then one could insist that, as long as they endorse both valence holism and weight holism, particularists have no need to accept noncombinatorialism. However, even when the objection has been strengthened in this way, my reply is the same since valence and weight holism both only concern how the contributory level depends on the underlying level. 
admit the existence of true and exceptionless contributory-to-overall principles. Moreover, debates about which contributory-to-overall principles are the correct ones will be instances of precisely the sort of moral theorizing that particularists are loath to engage in.

For example, suppose particularists concede that there is an additive combinatorial function. That does not yet settle the question of what the proper contributory-to-overall principles are, for there are many different additive combinatorial functions-many different ways of assigning rightness and wrongness to the actions available in a given context on the basis of comparing the total sum of reason in favor of each. This leaves us with questions like the following. Is the true additive combinatorial function a maximizing combinatorial function (so that the right actions in a given context are those with the greatest sum of reason in their favor), or is it a satisficing combinatorial function (so that the right actions are those with a suitable amount of total reason in their favor)? If the true combinatorial function involves satisficing, does it involve "absolute-level satisficing" (so that the amount of total reason in favor of an action that makes for rightness is the same in every context), or "comparative satisficing" (so that an action is right in a given context if and only if the total reason in its favor is greater than the total reason in favor of a reasonable percentage of the other available actions)? If the true combinatorial function involves maximizing, how does it handle situations in which the total reason function has no maximum (so that for every action that the agent might perform, there is another available action with a greater sum of reason in its favor)? Should we be worried that a maximizing additive combinatorial function would make morality too demanding (since for almost every action that any of us actually perform, there exists an alternate action with a slightly greater sum of reason in its favor that we could have performed instead)? And so on: these types of questions should look familiar, for they are exactly the sorts of issues that face consequentialists when they try to settle, for a given set of available actions, the connection between the total intrinsic value of each action's consequences and the overall rightness and wrongness of those actions. ${ }^{43}$ Moreover, just as particularists are dubious of the analogous debates in the consequentialist literature, so too are they likely to be deeply suspicious of this sort of back and

43. On maximizing versus satisficing versions of consequentialism, see Michael Slote, Common-Sense Morality and Consequentialism (London: Routledge \& Kegan Paul, 1985), chap. 3. On absolute-level versus comparative satisficing, see Thomas Hurka, "Two Kinds of Satisficing," Philosophical Studies 59 (1990): 107-11. On the worry that a maximizing version of consequentialism might make morality too demanding, see Shelly Kagan, The Limits of Morality (Oxford: Oxford University Press, 1989). 
forth over the most plausible version of an additive combinatorial function.

Matters are not helped if instead particularists insist that there exists a finitely expressible combinatorial function that is not additive in structure. To see this, consider two examples of works that spend some time searching for a nonadditive combinatorial function. In the penultimate chapter of The Possibility of Altruism, Thomas Nagel goes through great effort to show that the theory of reasons defended in his book need not be a version of consequentialism, and he does this by proposing various nonadditive 'combinatorial principles' that specify how the reasons present in a given situation determine one's overall duty-or in other words, does so by proposing various nonadditive, finitely expressible combinatorial functions. And in What We Owe to Each Other, T. M. Scanlon develops an elaborate contractualist theory of how rightness and wrongness is determined by the reasons present in a given circumstance-or in other words, develops a distinctively contractualist combinatorial function. But again, these works are instances of exactly the kind of moral theorizing that particularists are supposed to be suspicious of. What particularists really want is to insist that there is something misguided about Nagel and Scanlon's quest for true and illuminating contributory-to-overall principles, not to engage in a debate with Nagel and Scanlon over the particular merits and faults of their respective positions.

For this reason, I doubt that many true particularists would be content to simply renege on their noncombinatorialism. What recourse does this leave them, then, if they accept what I have argued here? I think a better option-though ultimately a far more radical one-would be for particularists to turn their back on the generalized weighing framework altogether. What underwrote that framework was a certain analogy, either with a literal weighing of elements on a scale or with physical forces acting on particles. Particularists want to move as far from those two analogies as possible while still working within the generalized weighing framework, but if my arguments are correct, there is a certain sense in which those analogies are essential to the weighing framework, a certain sense in which talk of reasons combining to determine the overall status of actions commits one to preserving those analogies, at least to some degree. Deviate too far from a strict analogy with weighing or with physical forces, and the framework falls apart. So perhaps particularists, if they want to preserve their general skepticism about our ability to limn the true and ultimate structure of the moral realm, should abandon talk of individual reasons or at least should give up the idea that reasons are the fundamental normative units that determine all other normative properties and relations.

Indeed, there is something truly bizarre about the picture of the 
moral realm that particularists wind up endorsing at the end of the day. On their picture, we can be completely confident that the proper metaphysics of morals has exactly three layers to it: the underlying level consisting in the nonnormative facts, the contributory level consisting in the facts about reasons and their valences and weights, and the overall level consisting in the facts about whatever normative properties and relations (such as rightness and wrongness) are determined by the interplay of those reasons. Also on this picture, we can be completely confident that we will never be able to fully discern the way in which the second level depends on the first, and the third level on the second. But why should there only be three layers to the picture? Why couldn't there be four levels, so that the values of the being-a-reason-for relation at the second level determine the values of some other normative relation at a third level, which in turn determine the overall moral status of the available actions at the final level? And if four, why not five or six or seven levels? And once we've started adding new levels to the picture, why aren't we on the road toward explicating the moral world, in the way in which natural science explains molecules in terms of atoms, atoms in terms of quarks, and quarks in terms of . . . ?

Thus, I think it would be more in keeping with the general sentiment behind particularism to cut out the middleman and drop all talk of individual reasons-or at least drop the claim that properties of reasons always determine the rightness and wrongness of actions. If one really wants to be a 'holist', in the true sense of that term, about normativity and claim that what normative properties a given feature has depends on every other feature of the situation at hand (on the whole situation, as we might put it), then any attempt to isolate individual normative elements-call them 'reasons'-in that situation will be artificial at best; really it is the entire situation, not any subportion of it, that gives a particular action the overall normative status that it has. (Recall the claims of holists about confirmation that it is an entire system of belief that is confirmed or disconfirmed, not individual portions of that system.) So perhaps what particularists really want, rather than the sort of three-level view they defend, is a two-level view according to which we have first the underlying level consisting of the nonnormative facts and then a second level consisting of whatever normative facts there may be, which obtain in virtue of the facts at the underlying level in an uncodifiable manner.

The problem with adopting this line, though, is that it deprives particularists of the existing arguments for their view-if we give up the generalized weighing framework and its assumptions that there are such things as individual reasons that determine other normative properties like rightness and wrongness, we lose the particularists' way of establishing (or at least attempting to establish) that there are no true and 
exceptionless moral principles. But this, I am sometimes inclined to think, is the fundamental problem with the particularist program. The guiding thought behind particularism is that ultimately the normative is incapable of being codified in an illuminating way, but how can we learn enough about the normative to know this without codifying the normative in at least one way? What particularists need is to provide enough structure to the moral realm for their arguments to get a grip, without thereby undermining their eventual conclusion that finite minds such as ours can never completely discern the true nature of that realm, and how to achieve that balancing trick is not easy to see. Thus, in the end I suspect that problems analogous to those raised in this article will face any attempt to give a positive argument for a view that is true to the spirit of particularism. That, by itself, does not mean that such a view must be false, but it does suggest that if the real position particularists are after is true, there is no way we could ever establish its truth. 